\title{
Original
}

\section{Hormonal and Genetical Assessment of a Japanese Girl with Weaver Syndrome}

\author{
Yoko Miyoshi ${ }^{1}$, Masako Taniike ${ }^{1}$, Ikuko Mohri ${ }^{1}$, Sotaro Mushiake ${ }^{1}$, \\ Shigeo Nakajima ${ }^{1}$, Naomichi Matsumoto ${ }^{2}$ and Keiichi Ozono ${ }^{1}$ \\ ${ }_{1}^{1}$ Department of Developmental Medicine (Pediatrics), Osaka University Graduate School of Medicine, Osaka, Japan, \\ ${ }^{2}$ Department of Human Genetics, Nagasaki University School of Medicine, Nagasaki, Japan; Department of Human \\ Genetics Yokohama City University Graduate School of Medicine, Yokohama, Japan
}

\begin{abstract}
We report a case of Japanese girl with a rare disorder of Weaver syndrome, which was characterized by overgrowth with advanced and disharmonic bone age, craniofacial abnormalities, developmental delay, metaphyseal flaring of the long bones and camptodactyly. The patient was delivered at 38 weeks of gestation with a length of $54.2 \mathrm{~cm}(+2.6 \mathrm{SD})$, a weight of $3805 \mathrm{~g}(+2.5 \mathrm{SD})$ and an occipitofrontal circumference (OFC) of $35.0 \mathrm{~cm}(+1.1 \mathrm{SD})$. She manifested hypertonia and flexion contractures in the first few years. She also had submucosal soft cleft palate and difficulty in swallowing and breathing in early infancy. When she was 5 years and 7 months old, her height and weight were 133.3 $\mathrm{cm}(+5.5 \mathrm{SD})$ and $32.0 \mathrm{~kg}(+5.1 \mathrm{SD})$, respectively. We could not detect any endocrinological abnormalities for the cause of overgrowth. According to clinical features, Weaver syndrome was suspected and genetical analysis was performed. Fluorescence in situ hybridization (FISH) and direct sequencing analysis showed neither deletion nor point mutation of the nuclear receptor SET-domain-containing protein 1 (NSD1) gene on $5 q 35$, which is responsible for Sotos syndrome. Therefore, we made a diagnosis of Weaver syndrome for this patient and discussed the differential diagnosis in terms of overgrowth syndrome.
\end{abstract}

Key words: Weaver syndrome, overgrowth, advanced bone age, Sotos syndrome, NSD1 gene

\section{Introduction}

Weaver syndrome (MIM 277590) is one of the overgrowth syndromes, which is characterized by excessive growth either of pre- or post-natal onset, craniofacial abnormalities (macrocephaly, round

Received: November 19, 2003

Accepted: January 16, 2004

Correspondence: Dr. Keiichi Ozono, Department of Developmental Medicine (Pediatrics), Osaka University Graduate School of Medicine, 2-2 Yamada-oka, Suita City, Osaka 565-0871, Japan

E-mail: keioz@ped.med.osaka-u.ac.jp face in infancy, broad forehead, flat occiput, ocular hypertelorism, long prominent philtrum, small dimpled chin, large low set ears and depressed nasal bridge), advanced and disharmonic bone age, developmental delay, metaphyseal flaring of the long bones and camptodactyly (1). Since Weaver et al reported this syndrome in 1974 (2), more than forty cases including five Japanese patients (3-5) have been reported. Most of the cases have been sporadic, and males have been affected more frequently than females (1). Since there has not been any obvious causative gene mapped or isolated so far, diagnosis of Weaver 
syndrome must be established by clinical features alone. However, clinical manifestations of Weaver syndrome overlap those of Sotos syndrome (MIM 117550) $(6,7)$, so that it is sometimes difficult to make a differential diagnosis. Excessive growth in childhood that is usually normalized by adulthood, characteristic face (macrodolichocephaly with frontal bossing, high hair line, long face, downslanting palpebral fissures, ocular hypertelorism, prominent jaw and highly arched palate), advanced bone age and developmental delay are observed in Sotos syndrome (8). Recently, a mutation of the NSD1 (MIM 606681; Genebank accession number, AF395588) gene on 5q35 has been reported to be a major cause of Sotos syndrome (9). The function of NSD1 remains largely unknown, and the mutation of this gene has been detected in certain cases of Weaver syndrome (10), suggesting that Sotos syndrome and Weaver syndrome might be allelic. To make a differential diagnosis, comprehensive assessment of the patient is required. Herein, we reported a typical case of Weaver syndrome with examination of the NSD1 gene.

\section{Case Report}

The patient was a 5 yr and 7 mo old Japanese female. Her parents were both healthy and unrelated. There was no family history of similarly affected individuals. Her father was $177 \mathrm{~cm}(+1.1$ SD) tall, and her mother was $169 \mathrm{~cm}(+2.1 \mathrm{SD})$ tall. After an uncomplicated pregnancy, she was vaginally delivered at $38 \mathrm{wk}$ of gestation with a length of $54.2 \mathrm{~cm}(+2.6 \mathrm{SD})$, a weight of $3805 \mathrm{~g} \mathrm{(+}$ $2.5 \mathrm{SD})$ and an $\mathrm{OFC}$ of $35.0 \mathrm{~cm}(+1.1 \mathrm{SD})$. Since no serious problems were noted except for the submucosal soft cleft palate, she was discharged at $5 \mathrm{~d}$ old. One week later she gradually showed dyspnea and cyanosis during sucking. She was hospitalized again for a survey of the respiratory problem at $20 \mathrm{~d}$ old. Similar to Pierre Robin sequence, a small mandible with glossoptosis caused cyanosis with stridor in the patient. She had a characteristic face: macrocephaly, broad forehead, ocular hypertelorism, long prominent philtrum and small dimpled chin. Large hands and feet, camptodactyly of both hands, flexion contractures of the elbows and knees, increased muscle tone and low-pitched hoarse cry were also noticed. Stridor and cyanosis gradually disappeared after tube feeding and head-up positioning started. As the oral intake increased, tube feeding was withdrawn. Accompanied by good appetite, subsequent growth accelerated and her height and weight became advanced for her age (Fig. 1). Radiographic survey of the extremities showed widening of the distal end of the long bones. The epiphyses of femoral capitus were large and slightly mottled. Serial surveillance of bone age demonstrated acceleration for age, and carpal bone age was more advanced to phalangeal bone age. Routine laboratory examinations were unremarkable. Both serum GH and IGF-1 levels were not elevated. High-resolution chromosomal analysis on peripheral blood lymphocytes demonstrated normal female karyotype. Judging from these clinical features including overgrowth, characteristic face and advanced bone age, the patient was diagnosed as having Weaver syndrome. Hypertonia and contractures gradually resolved. Motor development was within normal range, but language acquisition was mildly delayed. She underwent surgery for submucosal soft cleft palate at 18 mo old.

As the girl's growth was continuously advanced for her age (Fig. 1), she was re-evaluated at $5 \mathrm{yr}$ and $7 \mathrm{mo}$ old. Her height, weight and OFC were $133.3 \mathrm{~cm}(+5.5 \mathrm{SD}), 32.0 \mathrm{~kg}(+5.1 \mathrm{SD})$, and $56.8 \mathrm{~cm}(+4.1 \mathrm{SD})$, respectively. She showed craniofacial abnormalities: macrocephaly, broad forehead, flat occiput, ocular hypertelorism, downslanting palpebral fissures, long prominent philtrum, eversion of the lower lip with an openmouth appearance, small dimpled chin, large low set ears and depressed nasal bridge (Fig. 2). Hoarse low-pitched voice, large hands and feet, and mild camptodactyly of both hands were also 


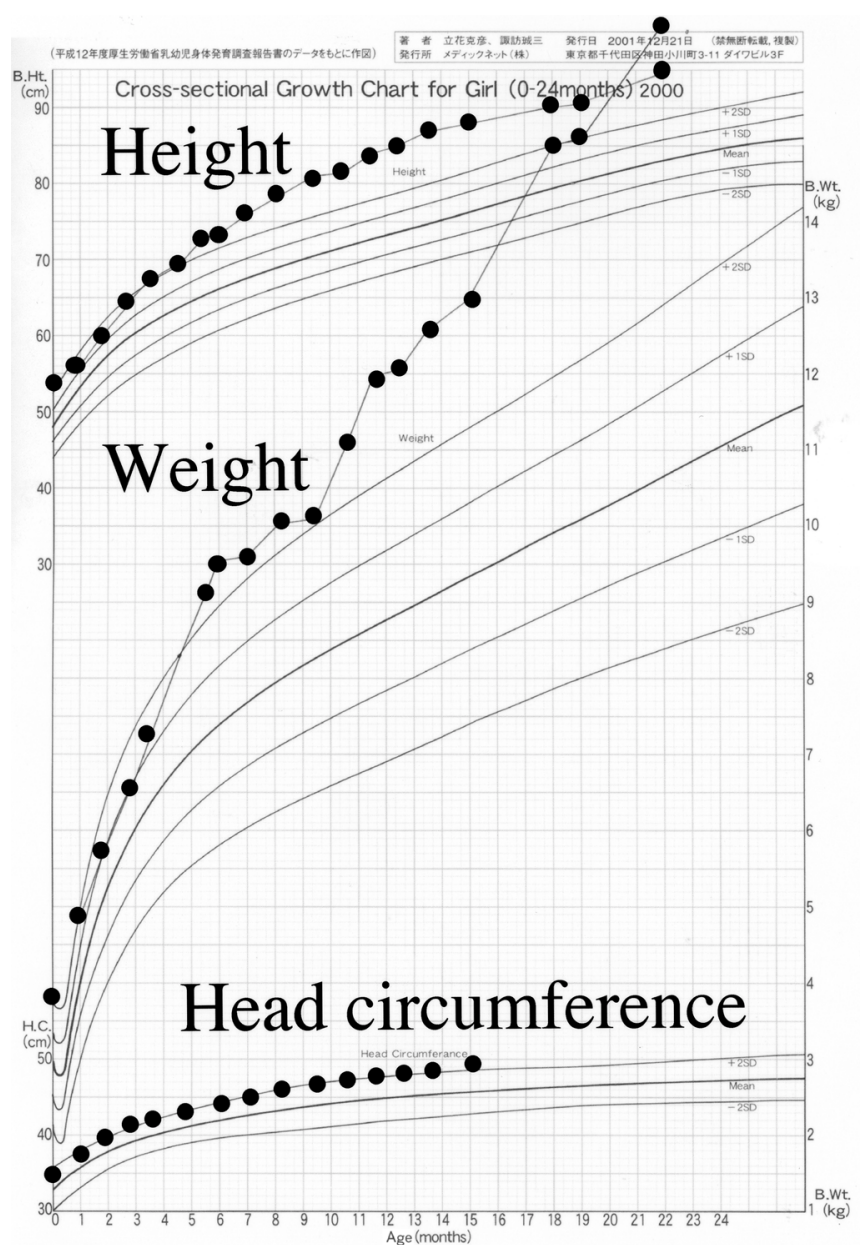

Fig. 1 Growth chart.

noticed. Breast development was in Tanner stage I. Neurological examination did not show any abnormal findings. She was shy toward strangers and tilted her head down when viewing her surroundings.

Routine serum and urinary laboratory investigations did not show any specific changes. Serum and urinary amino acid analyses were normal. Endocrinological survey to detect the cause of overgrowth revealed no obvious abnormalities: TSH $4.01 \mu \mathrm{U} / \mathrm{ml}$, freeT4 $1.3 \mathrm{ng} / \mathrm{dl}$, freeT3 $3.1 \mathrm{pg} / \mathrm{ml}$, FSH $1.6 \mathrm{mIU} / \mathrm{ml}, \mathrm{LH}<0.2 \mathrm{mIU} /$ $\mathrm{ml}, \mathrm{E} 2<10 \mathrm{pg} / \mathrm{ml}$, GH $3.3 \mathrm{ng} / \mathrm{ml}$, PTH 30.0 pg/ml, ACTH $59 \mathrm{pg} / \mathrm{ml}$, cortisol $7.8 \mu \mathrm{g} / \mathrm{dl}$. IGF-1 (78 ng/ $\mathrm{ml}$ ) was a little low for her age (91-344 ng/ml),

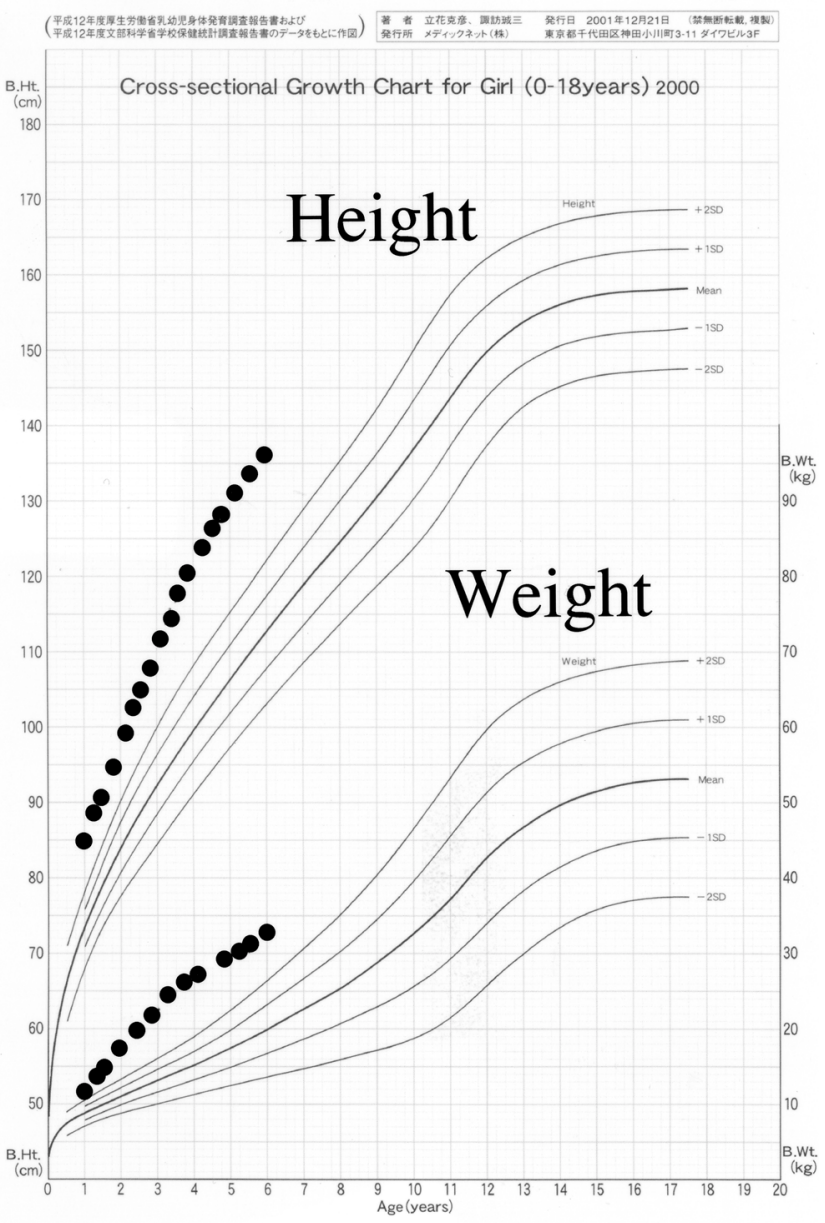

whereas IGFBP-3 $(2.69 \mu \mathrm{g} / \mathrm{ml})$ was normal for her age $(1.76-4.03 \mu \mathrm{g} / \mathrm{ml})$. Oral glucose tolerance test showed a normal glucose/insulin pattern and suppression of GH secretion. Normal responses of GH (basal 2.4, peak 18.7 ng/ml), FSH (basal 1.6, peak $15.5 \mathrm{mIU} / \mathrm{ml}$ ), LH (basal <0.2, peak $2.4 \mathrm{mIU} /$ $\mathrm{ml}$ ), TSH (basal 4.01, peak $21.09 \mu \mathrm{U} / \mathrm{ml}$ ), and prolactin (basal 6.5, peak $30.8 \mathrm{ng} / \mathrm{ml}$ ) were observed in response to appropriate stimulation of insulin-induced hypoglycemia, LH-releasing hormone and TRH. Elevated levels of osteocalcin ( $5.5 \mathrm{ng} / \mathrm{ml})$, bone alkaline phosphatase (138 IU/L) and urinary deoxypyridinoline (26.6 nmol/ mmol.Cre) indicated high turnover of bone metabolism. Radiographic studies showed 
(a)
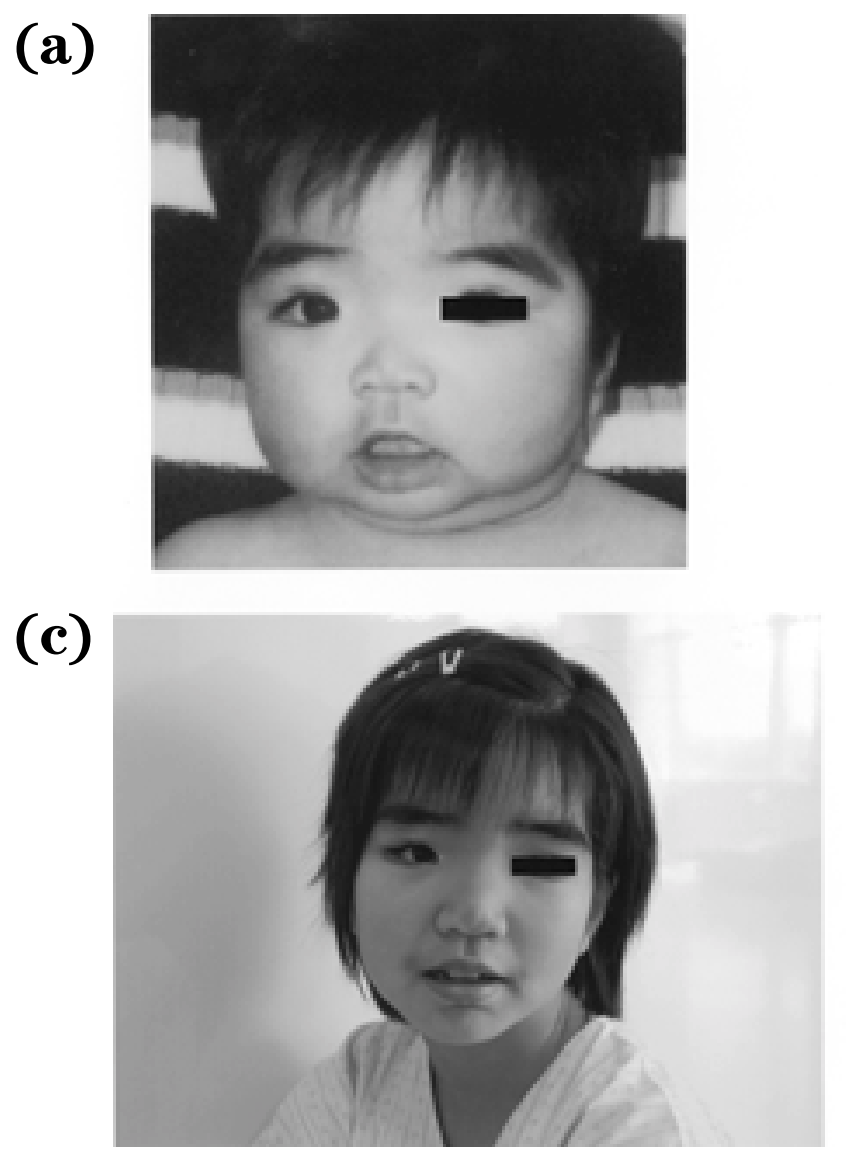

(b)

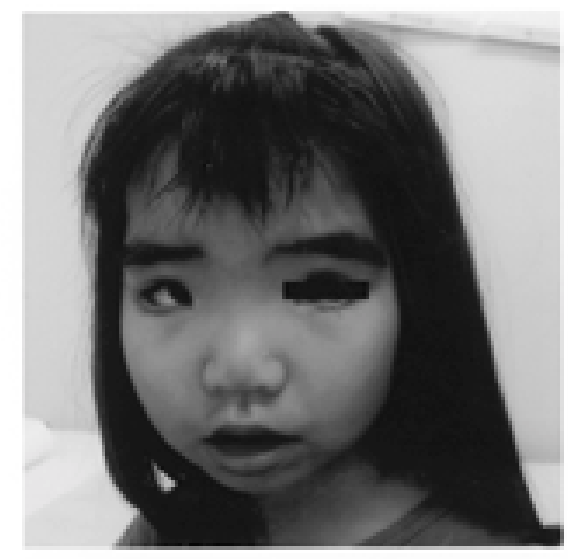

(d)

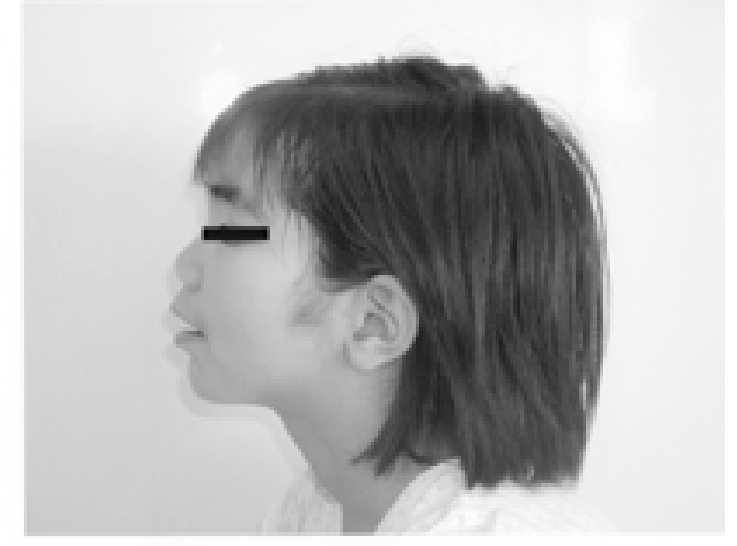

Fig. 2 Facial appearances of the patient (Permission was obtained from the parents). (a) 6 mo old, (b) 4 yr and 1 mo old, (c, d) 5 yr and 7 mo old.

accelerated disharmonic osseous maturation with carpal bone age of $8.6 \mathrm{yr}$ and phalangeal bone age of $7.1 \mathrm{yr}$ according to the Tanner-Whitehouse 2 method (Fig. 3a). Splaying of the distal femora was also demonstrated (Fig. 3b). Bone mineral density of the lumbar spine (L2-L4) was $0.785 \mathrm{~g} / \mathrm{cm}^{2}$, which was comparable to that of a 9 -yr-old girl. There were no abnormalities found in brain magnetic resonance imaging and fiberscopic investigation of the laryngopharynx. These clinical data prompted us to investigate the causative gene of overgrowth syndrome such as Sotos syndrome and Weaver syndrome. The deletion of the NSD1 gene, a causative gene of Sotos syndrome, was surveyed by FISH analysis on metaphase spreads prepared from peripheral lymphocytes (9). The mutation was surveyed by direct sequencing of exons 2-23 covering the whole coding region of NSD1, using genomic DNA extracted from peripheral leukocytes (11). Neither deletion nor a point mutation was found in the NSD1 gene.

\section{Discussion}

In this paper, we reported a patient with rare overgrowth disease, Weaver syndrome of which only about forty cases have been reported. The diagnosis of Weaver syndrome was made on the basis of major symptoms: i.e., excessive growth, craniofacial abnormalities, advanced and disharmonic bone age, and mental retardation. 

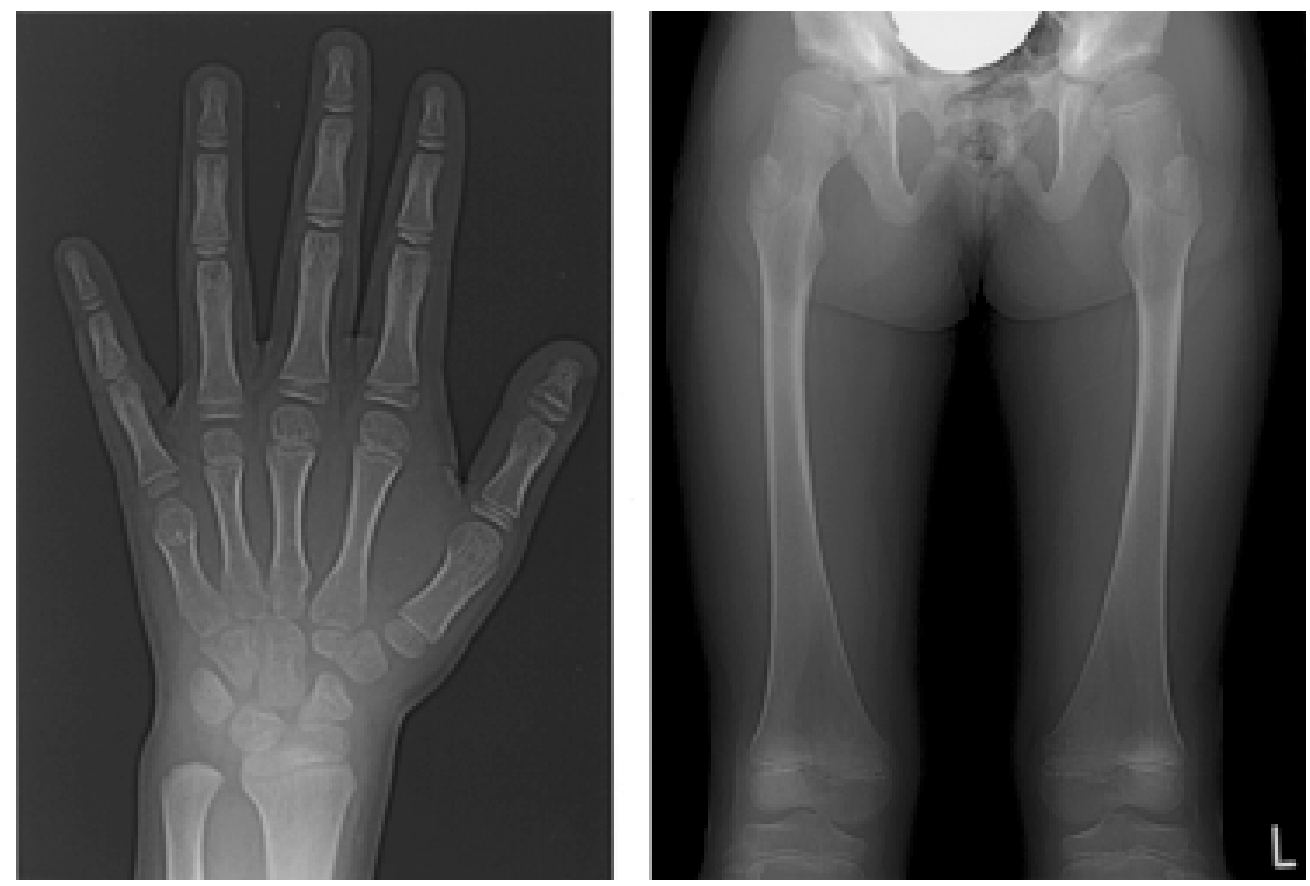

Fig. 3 Radiographic surveys of the left hand and femora at 5 yr and 7 mo old. (a) Accelerated disharmonic osseous maturation and short fifth metacarpal bone. (b) Splaying of the distal femora.

Differential diagnosis from Sotos syndrome is most important, because these two syndromes partially overlap. The clinical manifestations of Weaver syndrome and Sotos syndrome are shown in Table 1. In Sotos syndrome, despite overgrowth in infancy and childhood, final height is within normal limits for the population in most cases. In contrast, in the case of Weaver syndrome carpal bone age advances compared to phalangeal bone age and final height tends to be excessive.

Kurotaki et al. reported haploinsufficiency of the NSD1 gene on 5q35 in Sotos syndrome (9). They identified 50 microdeletions (45\%) and 16 point mutations (14\%) of NSD1 among 112 patients with Sotos syndrome, and indicated that $77 \%$ of individuals had either deletions or point mutations (12). Douglas et al. reported that NSD1 mutations were found in certain cases of Weaver syndrome (10). They demonstrated that 28 of 37 (76\%) patients with typical Sotos syndrome had mutations or deletions in the NSD1 gene, and that
3 of 7 (42\%) patients with Weaver syndrome had mutations. Recently, Turkman et al. identified mutations in the NSD1 gene in 18 of 20 (90\%) patients with Sotos syndrome (13). In contrast, they found no mutations of the NSD1 gene in five patients with Weaver syndrome, suggesting that these two syndromes might be different in terms of causative genes. Identification of the NSD1 gene as the causative gene in Sotos syndrome is a breakthrough for elucidating the mechanism of overgrowth. However, the function of the NSD1 gene product remains unclear, and certain cases with Sotos syndrome have neither deletion nor mutation of the NSD1 gene, suggesting that other causes also exist. This report demonstrates that there is at least one patient with Weaver syndrome who has no abnormalities of the NSD1 gene.

Since the final height in Weaver syndrome is predicted to be excessive, some therapy will be required in the near future to suppress our patient's growth. Voorhover et al. reported a girl 
Table 1 The clinical manifestations of Weaver syndrome and Sotos syndrome

\begin{tabular}{lll}
\hline & Weaver syndrome & Sotos syndrome \\
\hline overgrowth & common & common \\
\hline characteristic face & macrocephaly & macrodolichocephaly \\
& round face in infancy & long face \\
& broad forehead & frontal bossing \\
& ocular hyperterolism & ocular hyperterolism \\
& down-slanting palpebral fissures & down-slanting palpebral fissures \\
& long prominent philtrum & high hairline \\
& small dimpled chin & prominent jaw \\
& carpal $>$ phalangeal & carpal < phalangeal \\
advanced bone age & common & common \\
developmental delay & common & common \\
metaphyseal flaring of the long bones & rare & increased \\
advanced dental maturation & rare & almost normal \\
tumor formation & excessive & 28 of $37(76 \%)^{(10)}, 18$ of $20(90 \%)(13)$ \\
final height & 3 of $7(42 \%)^{(10), 0}$ of $5(0 \%)^{(13)}$ &
\end{tabular}

with Weaver syndrome who reached a final height of $186 \mathrm{~cm}$ (> 97th percentile) and weight of $85 \mathrm{~kg}$ (14). She was treated with high doses of estrogen from the age of 11 to $14.5 \mathrm{yr}$ in order to keep her final height within reasonable limits. Estrogen treatment induces growth plate fusion (15), thereby reducing the final height, but it might also increase the risk of malignancies of the breast and uterus later in life.

Further investigation of the etiology and pathophysiology of Weaver syndrome is needed to improve management of overgrowth in this syndrome.

\section{References}

1. Cole TRP, Dennis NR, Hughes HE. Weaver syndrome. J Med Genet 1992;29:332-7.

2. Weaver DD, Graham CB, Thomas IT, Smith DW. A new overgrowth syndrome with accelerated skeletal maturation, unusual faces, and camptodactyly. J Pediatr 1974;84:547-52.

3. Kondo I, Mori Y, Kuwajima K. Weaver Syndrome in Two Japanese Children. Am J Med Genet 1991;41:221-4.

4. Nishimura G, Hasegawa T, Nagai T. Propositus with Weaver syndrome and his mildly-affected mother: implication of nontraditional inheritance? [Letter]. Am J Med Genet 1996;65:249-51.

5. Ogawa A, Ishikiri Y, Kuroki H, Ishikawa N, Sugimoto K, Kawano Y. Clinical features of Weaver syndrome. Shonica 1999;40:986-9 (in Japanese).

6. Sotos JF, Dodge PR, Muirhead D, Crawford JD, Talbot NB. Cerebral gigantism in childhood: a syndrome of excessively rapid growth with acromegalic features and a nonprogressive neurologic disorder. N Eng J Med 1964;271:10916.

7. Opitz JM, Weaver DW, Reynolds JF Jr. The syndromes of Sotos and Weaver: reports and review. Am J Med Genet 1998;79:294-304.

8. Cole TRP, Hughes HE. Sotos syndrome: a study of the diagnostic criteria and natural history. J Med Genet 1994;31:20-32.

9. Kurotaki N, Imaizumi K, Harada N, Masuno M, Kondoh T, Nagai T, et al. Haploinsufficiency of NSD 1 causes Sotos syndrome. Nat Genet 2002;30:365-6.

10. Douglas J, Hanks S, Temple IK, Davies S, Murray A, Upadhyaya $\mathrm{M}$ et al. NSD1 mutations are the major cause of Sotos syndrome and occur in some cases of Weaver syndrome but are rare in other 
overgrowth phenotypes. Am J Hum Genet 2003;72:132-43.

11. Kurotaki N, Harada N, Yoshiura K, Sugano S, Niikawa N, Matsumoto N. Molecular characterization of NSD1, a human homologue of the mouse Nsd1 gene. Gene 2001;279:197-204.

12. Kurotaki N, Harada N, Shimokawa O, Miyake N, Kawame $\mathrm{H}$, Uetake K, et al. Fifty microdeletions among 112 cases of Sotos syndrome: low copy repeats possibly mediate the common deletion. Hum Mutat 2003;22:378-87.

13. Turkmen S, Gillessen-Kaesbach G, Meinecke P,
Albrecht B, Neumann LM, Hesse V, et al. Mutations in NSD1 are responsible for Sotos syndrome, but are not a frequent finding in other overgrowth phenotypes. Eur J Hum Genet 2003;11:858-65.

14. Voorhoeve PG, Van Gils JF, Jansen M. The difficulty of height prediction in Weaver syndrome. Clin Dysmorphol 2002;11:49-52.

15. Weise M, De-Levi S, Barnes KM, Gafni RI, Abad V, Baron J. Effects of estrogen on growth plate senescence and epiphyseal fusion. Proc Natl Acad Sci USA 2001;98:6871-6. 